\title{
Development and Validation of a Nomogram to Predict Deteriorating Trajectory in Patients with COVID-19 Infection: A Population-Based Prospective Study
}

\section{Wei Chen}

Hubei cancer hospital

Menglin Zhu

Enshi hospital

Jian Li

Enshi hospital

\section{Cuiping Pan}

Hubeicancer hospital

\section{Demian Zhao}

Hubei cancer hospital

\section{Yuting Jin}

Hubei cancer hospital

Manxiu Li

Hubei cancer hospital

\section{Shun Wu}

Hubei cancer hospital

\section{Yaojun Feng}

Hubei cancer hospital

Tiejun Wang ( $\nabla$ tiejunwanghp@163.com )

Hubei Cancer Hospital

\section{Research}

Keywords: COVID-19, mild-moderate patients, severe probability, nomogram score

Posted Date: June 2nd, 2020

DOl: https://doi.org/10.21203/rs.3.rs-30640/v1

License: (c) (i) This work is licensed under a Creative Commons Attribution 4.0 International License. Read Full License 
Page 2/14 


\section{Abstract}

Background Most of the patients with COVID-19 infection are mild to moderate initially. However, there is no effective prediction for the patients to develop into severe or extremely severe. This study aims to develop an effective clinical prediction model.

Methods A single-center, retrospective, observational study conducted. A nomogram was conducted based on the results of multivariate logistic regression analysis.

Results A total of 483 patients diagnosed mild to moderate were included, among these patients 62 developed severe or extremely critical illness. Seven variables including hyperlipidemia, vomiting, diarrhea, lymphocyte, imaging and mentality were associated with deteriorating trajectory. The ROC curve showed that model was robust, for which the area under the curve of the training set and the validation set are 0.873 and 0.813 .

Conclusions For patients with mild to moderate COVID-19 infection, nomogram score can effectively predict the possibility of patients developing into severe or extremely critical.

\section{Background}

Since December 2019, COVID-19 has shown an outbreak trend. This new coronavirus has swept the world since Wuhan, China. As of June 2020, the number of people worldwide who had confirmed the diagnosis of COVID-19 had exceeded one million ${ }^{[1,2]}$.Starting from the evolution of the patient's condition, the majority of patients with COVID-19 infection are mild and moderate, and only a small number of patients are severe and extremely critical. However, even if the patient is diagnosed as mild or moderate, which still needs to be effectively isolated, because COVID-19 has significant human-to-human characteristics $^{[3]}$.

The Chinese government quickly deployed and established a sheltered hospital for accommodating patients with mild to moderate COVID-19, and achieved remarkable results ${ }^{[4]}$. Therefore, it is very important to carry out early isolation of mild to moderate patients, and to predict and intervene in patients who may develop into severe and extremely severe diseases.

To the best of our knowledge, existing studies have reported risk factors for COVID-19 patients to develop severe or very critical illnesses, but few reports have analyzed and studied the development of mild to moderate patients to severe illnesses ${ }^{[3,5,6]}$. In particular, there is a lack of predictive analysis of mild to moderate patients who may develop into severe illness.

Collectively, prediction of risk factors seems to be a promising way for predicting severe probability after COVID-19 infection. Here, we conducted a prospective observational study based on the nomogram score to evaluate patients who diagnosed with COVID-19 developed from mild or moderate to severe probability. 


\section{Methods}

\section{Patients recruitment}

A single-center, retrospective, observational study was conducted from the Wuchang mobile cabin hospital built by converting public venues. We retrospectively analyzed 483 patients diagnosed with mild to moderate COVID-19 infection from Feb 6, 2020, to Feb 15, 2020. All patients diagnosed with COVID-19 infection according to the "New Coronavirus Infected Pneumonia Diagnosis and Treatment Plan (Trial Version 5)" during the study period ${ }^{[4]}$. This study was approved by the Ethics Commission of Hubei Cancer Hospital (LLHBCH2020LW-001). This was a secondary analysis. Previous research results have been announced by the Chinese Clinical Trial Registry. The clinical trial registration (http://www.chictr.org.cn) number was ChiCTR2000030858.

\section{Data collection}

Data collection such as demographic and epidemiological information, laboratory findings, nursing records, imaging information, and treatment were obtained from electronic medical records. To make sure that all patients were followed-up, two researchers independently reviewed and verified the data by telephone communication. By March 9, 2020, 62 patients who were transferred to a designated hospital.

\section{Statistical analysis}

Continuous variables were described as the mean (standard deviation [SD]). Two-tailed $t$ test or MannWhitney test was used for continuous variables analysis. Categorical variables were compared using the $\chi 2$ test or Fisher exact test. Stepwise multivariable logistic regression was performed to identify deterioration factors associated with serious illness. A nomogram was conducted based on the results of multivariate logistic regression analysis herein. Patients were randomly divided into the training and validation samples. The predictive performance of the nomogram was evaluated via concordance index and calibration curve. To accurately decrease the overfit bias, 1000 bootstrap samples was performed. Pvalue $<0.05$ was considered to be statistically significant. All analyses were conducted using the $R$ statistical package (v.3.5.2; R Foundation for Statistical Computing, Vienna, Austria; https://www.rproject.org).

\section{Results}

\section{Demographics and clinical characteristics}

A total of 483 patients diagnosed mild to moderate from the mobile cabin hospital in Wuchang, Wuhan were included in this study. Among them, 62 patients developed severe or extremely critical illness during isolation observation and treatment. According to the principle of random grouping, 70\% (339) of the patients are used to train the model, and $30 \%(144)$ of the patients are used to verify the model. The patient information of the two sets has been displayed through Table 1. 
Table 1

Demographics and clinical characteristics in the training and validation cohort

\begin{tabular}{|c|c|c|c|c|}
\hline \multirow[t]{2}{*}{ variable } & \multicolumn{2}{|c|}{ Training cohort } & \multicolumn{2}{|c|}{ Validation cohort } \\
\hline & Mild & Severe & Mild & Severe \\
\hline & $(n=293)$ & $(n=46)$ & $(n=128)$ & $(n=16)$ \\
\hline
\end{tabular}

Age, $y$

0.94

Mean $( \pm$ SD)

$48.3( \pm 12.2)$

$49.0( \pm 13.0)$

$48.8( \pm 12.8)$

$45.7( \pm 12.7)$

Gender

0.92

female

$156(53.2 \%) \quad 30(65.2 \%)$

$71(55.5 \%)$

8 (50.0\%)

male

$137(46.8 \%) \quad 16(34.8 \%)$

$57(44.5 \%)$

$8(50.0 \%)$

BMI, $\mathrm{kg} / \mathrm{m}^{2}$

$\operatorname{Mean}( \pm \mathrm{SD})$

$23.3( \pm 3.16) \quad 23.0( \pm 3.16)$

$23.4( \pm 3.13)$

$24.7( \pm 2.86)$

Exercise

No

$108(36.9 \%) \quad 21(45.7 \%)$

$55(43.0 \%)$

$5(31.2 \%)$

Yes

$185(63.1 \%)$

$25(54.3 \%)$

$73(57.0 \%)$

$11(68.8 \%)$

Smoking

0.85

no

$240(81.9 \%)$

$31(67.4 \%)$

$101(78.9 \%)$

$13(81.2 \%)$

yes

$53(18.1 \%)$

$15(32.6 \%)$

$27(21.1 \%)$

3 (18.8\%)

Surgery

No

Yes

$61(20.8 \%)$

$2(4.3 \%)$

$232(79.2 \%)$

$44(95.7 \%)$

$90(70.3 \%)$

0.39

Antiviral treatment

No

Yes

97 (33.1\%)

$14(30.4 \%)$

47 (36.7\%)

$6(37.5 \%)$

196 (66.9\%)

$32(69.6 \%)$

81 (63.3\%)

$10(62.5 \%)$

Antibiotic treatment

No

$114(38.9 \%)$

$17(37.0 \%)$

$56(43.8 \%)$

$6(37.5 \%)$

Abbreviations: BMI: Body Mass Index; SD: standard deviation. Hypertension: $\geq 140$ / $90 \mathrm{mmHg}$.

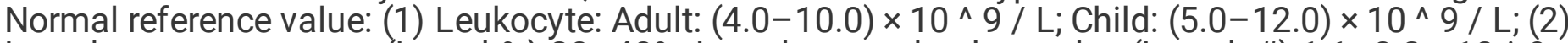
Lymphocyte percentage (Lymph\%) 20-40\%; Lymphocyte absolute value (Lymph \#) 1.1-3.2×10^ 9; (3) Fasting whole blood glucose: $3.9 \sim 6.1 \mathrm{mmol} / \mathrm{L}, 1$ hour after meal: $6.7 \sim 9.4 \mathrm{mmol} / \mathrm{L}, 2$ hours after meal: $\leq 7.8 \mathrm{mmol} / \mathrm{L}$. Heart function: Tachycardia (100 beats / min). Liver function: ALT 0$46 \mathrm{U} / \mathrm{L} ;$ AST 0-46 U/L. Urine infection: Creatinine (30-110 $\mu \mathrm{mol} / \mathrm{L})$. 


\begin{tabular}{|c|c|c|c|c|c|}
\hline Yes & 179 (61.1\%) & $29(63.0 \%)$ & 72 (56.2\%) & $10(62.5 \%)$ & \\
\hline \multicolumn{5}{|l|}{ Hypertension } & \multirow[t]{3}{*}{0.63} \\
\hline No & 260 (88.7\%) & 44 (95.7\%) & $111(86.7 \%)$ & $16(100 \%)$ & \\
\hline Yes & $33(11.3 \%)$ & $2(4.3 \%)$ & $17(13.3 \%)$ & $0(0 \%)$ & \\
\hline \multicolumn{5}{|l|}{ Diabetes } & \multirow[t]{3}{*}{0.60} \\
\hline No & 278 (94.9\%) & 43 (93.5\%) & $123(96.1 \%)$ & 15 (93.8\%) & \\
\hline Yes & $15(5.1 \%)$ & $3(6.5 \%)$ & $5(3.9 \%)$ & $1(6.2 \%)$ & \\
\hline \multicolumn{5}{|l|}{ Hyperlipidemia } & \multirow[t]{3}{*}{0.25} \\
\hline No & 286 (97.6\%) & $42(91.3 \%)$ & $126(98.4 \%)$ & $16(100 \%)$ & \\
\hline Yes & $7(2.4 \%)$ & $4(8.7 \%)$ & $2(1.6 \%)$ & $0(0 \%)$ & \\
\hline \multicolumn{5}{|l|}{ Malignant } & \multirow[t]{3}{*}{0.62} \\
\hline No & 290 (99.0\%) & 46 (100\%) & $126(98.4 \%)$ & $16(100 \%)$ & \\
\hline Yes & $3(1.0 \%)$ & $0(0 \%)$ & $2(1.6 \%)$ & $0(0 \%)$ & \\
\hline \multicolumn{5}{|l|}{ Temperature, ${ }^{\circ} \mathrm{C}$} & \multirow[t]{2}{*}{1.00} \\
\hline Mean $( \pm S D)$ & $37.7( \pm 0.832)$ & $37.8( \pm 0.918)$ & $37.6( \pm 0.907)$ & $38.3( \pm 0.690)$ & \\
\hline \multicolumn{5}{|l|}{ Cough } & \multirow[t]{3}{*}{0.21} \\
\hline No & 117 (39.9\%) & 20 (43.5\%) & $58(45.3 \%)$ & $9(56.2 \%)$ & \\
\hline Yes & 176 (60.1\%) & $26(56.5 \%)$ & $70(54.7 \%)$ & $7(43.8 \%)$ & \\
\hline \multicolumn{5}{|l|}{ Headache } & \multirow[t]{3}{*}{0.19} \\
\hline No & 228 (77.8\%) & 34 (73.9\%) & $105(82.0 \%)$ & 14 (87.5\%) & \\
\hline Yes & $65(22.2 \%)$ & $12(26.1 \%)$ & $23(18.0 \%)$ & $2(12.5 \%)$ & \\
\hline \multicolumn{5}{|l|}{ Chest tightness } & \multirow[t]{3}{*}{0.65} \\
\hline No & 216 (73.7\%) & $29(63.0 \%)$ & 98 (76.6\%) & $9(56.2 \%)$ & \\
\hline Yes & 77 (26.3\%) & $17(37.0 \%)$ & $30(23.4 \%)$ & $7(43.8 \%)$ & \\
\hline \multicolumn{5}{|l|}{ Vomiting } & 0.94 \\
\hline \multicolumn{6}{|c|}{$\begin{array}{l}\text { Abbreviations: BMI: Body Mass Index; SD: standard deviation. Hypertension: } \geq 140 / 90 \mathrm{mmHg} \text {. } \\
\text { Normal reference value: (1) Leukocyte: Adult: }(4.0-10.0) \times 10^{\wedge} 9 / \mathrm{L} \text {; Child: }(5.0-12.0) \times 10^{\wedge} 9 / \mathrm{L} ;(2) \\
\text { Lymphocyte percentage (Lymph\%) } 20-40 \% \text {; Lymphocyte absolute value (Lymph \#) } 1.1-3.2 \times 10^{\wedge} 9 \text {; } \\
\text { (3) Fasting whole blood glucose: } 3.9 \sim 6.1 \mathrm{mmol} / \mathrm{L}, 1 \text { hour after meal: } 6.7 \sim 9.4 \mathrm{mmol} / \mathrm{L}, 2 \text { hours } \\
\text { after meal: } \leq 7.8 \mathrm{mmol} / \mathrm{L} \text {. Heart function: Tachycardia }(100 \text { beats / min). Liver function: ALT 0- } \\
46 \mathrm{U} / \mathrm{L} \text {; AST } 0-46 \mathrm{U} / \mathrm{L} \text {. Urine infection: Creatinine }(30-110 \mu \mathrm{mol} / \mathrm{L}) \text {. }\end{array}$} \\
\hline
\end{tabular}




\begin{tabular}{|c|c|c|c|c|c|}
\hline No & $246(84.0 \%)$ & $45(97.8 \%)$ & 109 (85.2\%) & 15 (93.8\%) & \\
\hline Yes & $47(16.0 \%)$ & $1(2.2 \%)$ & $19(14.8 \%)$ & $1(6.2 \%)$ & \\
\hline \multicolumn{5}{|l|}{ Diarrhea } & \multirow[t]{3}{*}{0.92} \\
\hline No & 275 (93.9\%) & 39 (84.8\%) & $120(93.8 \%)$ & $13(81.2 \%)$ & \\
\hline Yes & $18(6.1 \%)$ & $7(15.2 \%)$ & $8(6.2 \%)$ & $3(18.8 \%)$ & \\
\hline \multicolumn{5}{|l|}{ Leukocyte } & \multirow[t]{3}{*}{0.18} \\
\hline abnormal & $72(24.6 \%)$ & 18 (39.1\%) & 25 (19.5\%) & $5(31.2 \%)$ & \\
\hline normal & $221(75.4 \%)$ & $28(60.9 \%)$ & 103 (80.5\%) & $11(68.8 \%)$ & \\
\hline \multicolumn{5}{|l|}{ Lymphocyte } & \multirow[t]{3}{*}{0.31} \\
\hline abnormal & 49 (16.7\%) & $16(34.8 \%)$ & 15 (11.7\%) & $7(43.8 \%)$ & \\
\hline normal & $244(83.3 \%)$ & 30 (65.2\%) & $113(88.3 \%)$ & $9(56.2 \%)$ & \\
\hline \multicolumn{5}{|l|}{ Thrombocyte } & \multirow[t]{3}{*}{0.45} \\
\hline abnormal & $48(16.4 \%)$ & $11(23.9 \%)$ & 19 (14.8\%) & $2(12.5 \%)$ & \\
\hline normal & $245(83.6 \%)$ & 35 (76.1\%) & 109 (85.2\%) & $14(87.5 \%)$ & \\
\hline \multicolumn{5}{|l|}{ Renal function } & \multirow[t]{3}{*}{0.85} \\
\hline No & $293(100 \%)$ & 38 (82.6\%) & 127 (99.2\%) & $14(87.5 \%)$ & \\
\hline Yes & $0(0 \%)$ & $8(17.4 \%)$ & $1(0.8 \%)$ & $2(12.5 \%)$ & \\
\hline \multicolumn{5}{|l|}{ Heart function } & \multirow[t]{3}{*}{0.56} \\
\hline No & $289(98.6 \%)$ & 37 (80.4\%) & 127 (99.2\%) & $13(81.2 \%)$ & \\
\hline Yes & $4(1.4 \%)$ & $9(19.6 \%)$ & $1(0.8 \%)$ & $3(18.8 \%)$ & \\
\hline \multicolumn{5}{|l|}{ Urine infection } & \multirow[t]{3}{*}{0.66} \\
\hline No & $266(90.8 \%)$ & 38 (82.6\%) & 117 (91.4\%) & $14(87.5 \%)$ & \\
\hline Yes & 27 (9.2\%) & $8(17.4 \%)$ & $11(8.6 \%)$ & $2(12.5 \%)$ & \\
\hline \multicolumn{5}{|l|}{ Imaging test } & \multirow[t]{2}{*}{0.27} \\
\hline normal & $288(98.3 \%)$ & 31 (67.4\%) & 127 (99.2\%) & $12(75.0 \%)$ & \\
\hline \multicolumn{6}{|c|}{$\begin{array}{l}\text { Abbreviations: BMI: Body Mass Index; SD: standard deviation. Hypertension: } \geq 140 / 90 \mathrm{mmHg} \text {. } \\
\text { Normal reference value: (1) Leukocyte: Adult: (4.0-10.0) } \times 10^{\wedge} 9 / \mathrm{L} \text {; Child: }(5.0-12.0) \times 10^{\wedge} 9 / \mathrm{L} \text {; (2) } \\
\text { Lymphocyte percentage (Lymph\%) 20-40\%; Lymphocyte absolute value (Lymph \#) } 1.1-3.2 \times 10^{\wedge} 9 ; \\
\text { (3) Fasting whole blood glucose: } 3.9 \sim 6.1 \mathrm{mmol} / \mathrm{L}, 1 \text { hour after meal: } 6.7 \sim 9.4 \mathrm{mmol} / \mathrm{L}, 2 \text { hours } \\
\text { after meal: } \leq 7.8 \mathrm{mmol} / \mathrm{L} \text {. Heart function: Tachycardia (100 beats / min). Liver function: ALT 0- } \\
46 \mathrm{U} / \mathrm{L} \text {; AST } 0-46 \mathrm{U} / \mathrm{L} \text {. Urine infection: Creatinine }(30-110 \mu \mathrm{mol} / \mathrm{L}) \text {. }\end{array}$} \\
\hline
\end{tabular}




\begin{tabular}{|llllll|}
\hline abnormal & $5(1.7 \%)$ & $15(32.6 \%)$ & $1(0.8 \%)$ & $4(25.0 \%)$ & \\
\hline Mentality & & & & & \\
\hline nervous & $92(31.4 \%)$ & $24(52.2 \%)$ & $46(35.9 \%)$ & $4(25.0 \%)$ & \\
\hline without nervous & $201(68.6 \%)$ & $22(47.8 \%)$ & $82(64.1 \%)$ & $12(75.0 \%)$ & \\
\hline
\end{tabular}

Abbreviations: BMI: Body Mass Index; SD: standard deviation. Hypertension: $\geq 140$ / $90 \mathrm{mmHg}$. Normal reference value: (1) Leukocyte: Adult: $(4.0-10.0) \times 10^{\wedge} 9 /$ L; Child: $(5.0-12.0) \times 10^{\wedge} 9 / \mathrm{L}$; (2) Lymphocyte percentage (Lymph\%) 20-40\%; Lymphocyte absolute value (Lymph \#) 1.1-3.2×10^ 9; (3) Fasting whole blood glucose: $3.9 \sim 6.1 \mathrm{mmol} / \mathrm{L}, 1$ hour after meal: $6.7 \sim 9.4 \mathrm{mmol} / \mathrm{L}$, 2 hours after meal: $\leq 7.8 \mathrm{mmol} / \mathrm{L}$. Heart function: Tachycardia (100 beats / min). Liver function: ALT 0$46 \mathrm{U} / \mathrm{L}$; AST 0-46 U/L. Urine infection: Creatinine (30-110 $\mu \mathrm{mol} / \mathrm{L})$.

\section{Multivariate logistic regression analysis of deterioration factors}

In order to establish a reliable prediction model, a total of thirty variables were included in this study for screening. After multivariate logistics stepwise regression analysis, there were seven variables (hyperlipidemia, vomiting, diarrhea, lymphocyte, imaging, mentality) that met the modeling criteria. Considering that age has a greater influence on the robustness of the model, for which also included in this model construction, and the relevant variables have been shown in Table 2.

Table 2

Multivariable logistic regression analysis for deteriorating factors for predicting development of severe cases

\begin{tabular}{|llll|}
\hline variablest & Odds ratio & $95 \% \mathrm{Cl}$ & P value \\
\hline Age & 0.58 & $0.30-1.14$ & $<0.10^{£}$ \\
\hline Hyperlipidemia (yes vs no) & 8.49 & $1.40-51.37$ & $<0.05$ \\
\hline Vomiting (yes vs no) & 0.003 & $0.00-0.07$ & $<0.01$ \\
\hline Diarrhea (yes vs no) & 3.51 & $1.17-10.58$ & $<0.05$ \\
\hline Lymphocyte (normal vs abnormal) & 2.65 & $1.13-6.18$ & $<0.05$ \\
\hline Imaging (normal vs abnormal) & 220.53 & $25.94-1875.10$ & $<0.01$ \\
\hline Mentality (normal vs nervous) & 3.27 & $1.45-7.34$ & $<0.01$ \\
\hline †. adjusted model: & & & \\
\hline Model1, body temperature was adjusted. C-index:0.874. & & \\
\hline Model2, gender was adjusted. C-index:0.873. & & \\
\hline Model3, age was adjusted. C-index:0.858. & & \\
\hline £. age is considered as significant variable for great influence on model adjustment. \\
\hline
\end{tabular}




\section{Construction of a nomogram score based on risk factors}

The deterioration trajectories associated with serious illness was constructed based on the coefficients from the seven meaningful variables. According to the construction principle of nomogram score, each variable will be given different scores and weights. Patients can evaluate the score of each variable in turn according to their clinical characteristics and auxiliary examination results, and then summarize according to the total score of seven variables. Based on the total score, the patient can determine the probability of developing severe or extremely critical illness. The nomogram score was shown in Fig. 1.

\section{Model accuracy evaluation by calibration curve and ROC analysis}

In order to further verify the robustness of the model, the calibration curve and ROC curve are used to evaluate the pros and cons of the model. The results show that the prediction capabilities of the training set and the test set are highly consistent. The ROC curve shows that the area under the curve of the training set and the validation set are 0.873 and 0.813 , respectively. The detailed information has been shown in Fig. 2 and Fig. 3.

\section{Discussion}

The use of the nomogram score in estimating the risk of patients diagnosed with mild or moderate harboring severe probability to direct clinical treatment is a new concept ${ }^{[7]}$. Previous studies have attempted to use multivariate risk analysis to evaluate patient's condition changes ${ }^{[8-10]}$. However, the significance of accurately assessing that a patient may develop into severe or extremely critical illness is still lacking.

In the deteriorating trajectory prediction nomogram, the patient's subjective feelings and auxiliary diagnosis results were included in the model. These variables are versatile and quantifiable, so that they can be directly used for patient self-evaluation. Previous study has reported that age could act as an important independent predictor of mortality in SARS and MERS ${ }^{[11,12]}$. However, our study showed that age was not associated with severity development instead of contributing to the prediction model, which demonstrated that age should not be neglected in the disease progression. With the help of the clinical prediction model we established, patients can predict the probability of their own disease progression in advance, and also optimize the allocation of medical resources, which helps clinicians to optimize and make effective treatment decisions.

Similarly, our research also had several limitations as follows. First, this was a retrospective cohort study. Although based on the real world, the clinical information of patients is inevitably biased. Second, we mainly used single-center data to build up a prediction model, and also verify the robustness of the model internally, but external data is still required for model verification, especially multi-center clinical prediction is necessary. Third, this study mainly focused on the patient's clinical information and auxiliary 
examination, and the patient's subsequent treatment effects are also needed to be fully evaluated in order to obtain a better predictive effect.

\section{Conclusion}

In this study, we established a clinical prediction model that can predict the development of mild to moderate patients to severe or extremely critical. Evaluating the deterioration trajectory of COVID-19 patients can help optimize the allocation of scarce medical resources.

\section{Abbreviations}

SD: standard deviation; ROC curve: receiver operating characteristic curve; ChiCTR: Chinese Clinical Trial Registry.

\section{Declarations}

\section{Ethics approval and consent to participate}

This study was approved by the Ethics Commission of Hubei Cancer Hospital (LLHBCH2020LW-001).

\section{Consent for publication}

This study was approved for publication by the Chinese Clinical Trial Registry (ChiCTR2000030858).

\section{Availability of data and materials}

The data connection:

tiejun, Wang (2020), COVID-19, Dryad, Dataset, https://doi.org/10.5061/dryad.kwh70rz13

\section{Competing interests}

We declare no competing interests.

\section{Funding}

This study was supported by grants from the National Natural Foundation of China (No.81172467).

\section{Author contributions}


Wei Chen, Menglin Zhu and Tiejun Wang developed the original concept and study design. Jian Li, Cuiping Pan, Demian Zhao, Yuting Jin generated the initial draft of the manuscript. Manxiu Li, Shun Wu and Yaojun Feng completed the data analysis. All authors contributed to the interpretation of the findings and approved the final manuscript version.

\section{Acknowledgements}

Not applicable

\section{References}

1. Kannan, S., et al., COVID-19 (Novel Coronavirus 2019) - recent trends. Eur Rev Med Pharmacol Sci, 2020. 24(4): p. 2006-2011.

2. Ahn, D.G., et al., Current Status of Epidemiology, Diagnosis, Therapeutics, and Vaccines for Novel Coronavirus Disease 2019 (COVID-19). J Microbiol Biotechnol, 2020. 30(3): p. 313-324.

3. Zhou, F., et al., Clinical course and risk factors for mortality of adult inpatients with COVID-19 in Wuhan, China: a retrospective cohort study. Lancet, 2020. 395(10229): p. 1054-1062.

4. Chen, S., et al., Fangcang shelter hospitals: a novel concept for responding to public health emergencies. Lancet, 2020. 395(10232): p. 1305-1314.

5. Li, Q., et al., Early Transmission Dynamics in Wuhan, China, of Novel Coronavirus-Infected Pneumonia. N Engl J Med, 2020. 382(13): p. 1199-1207.

6. Liang, W., et al., Development and Validation of a Clinical Risk Score to Predict the Occurrence of Critical IIIness in Hospitalized Patients With COVID-19. JAMA Intern Med, 2020.

7. lasonos, A., et al., How to build and interpret a nomogram for cancer prognosis. J Clin Oncol, 2008. 26(8): p. 1364-70.

8. Ali, H., et al., Survival rate in acute kidney injury superimposed COVID-19 patients: a systematic review and meta-analysis. Ren Fail, 2020. 42(1): p. 393-397.

9. Alqahtani, J.S., et al., Prevalence, Severity and Mortality associated with COPD and Smoking in patients with COVID-19: A Rapid Systematic Review and Meta-Analysis. PLoS One, 2020. 15(5): p. e0233147.

10. Lippi, G., J. Wong, and B.M. Henry, Hypertension in patients with coronavirus disease 2019 (COVID19): a pooled analysis. Pol Arch Intern Med, 2020. 130(4): p. 304-309.

11. Choi, K.W., et al., Outcomes and prognostic factors in 267 patients with severe acute respiratory syndrome in Hong Kong. Ann Intern Med, 2003. 139(9): p. 715-23.

12. Matsuyama, R., et al., Clinical determinants of the severity of Middle East respiratory syndrome (MERS): a systematic review and meta-analysis. BMC Public Health, 2016. 16(1): p. 1203.

\section{Figures}


Points

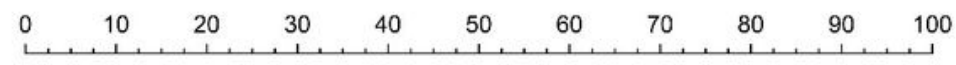

Age

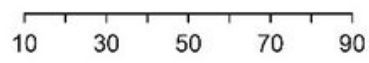

Hyperlipidemia

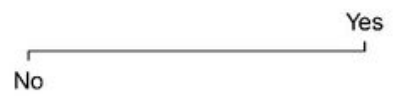

Vomiting

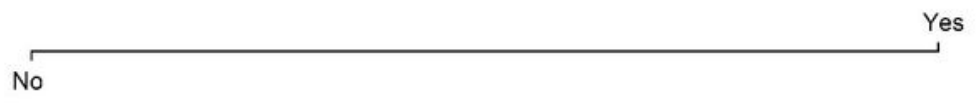

Diarrhea

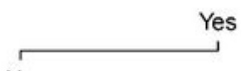

No

Lymphocyte

Abnormal

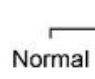

Imaging

Normal

Mentality

Without nervous

Total Points

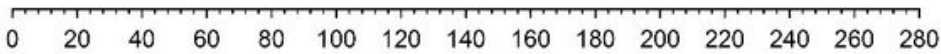

Deterioration probability

(From mild to severe)

$\begin{array}{llllll}0.001 & 0.01 & 0.1 & 0.5 & 0.9 & 0.99\end{array}$

\section{Figure 1}

Nomogram score for predicting development of severe probability 
A

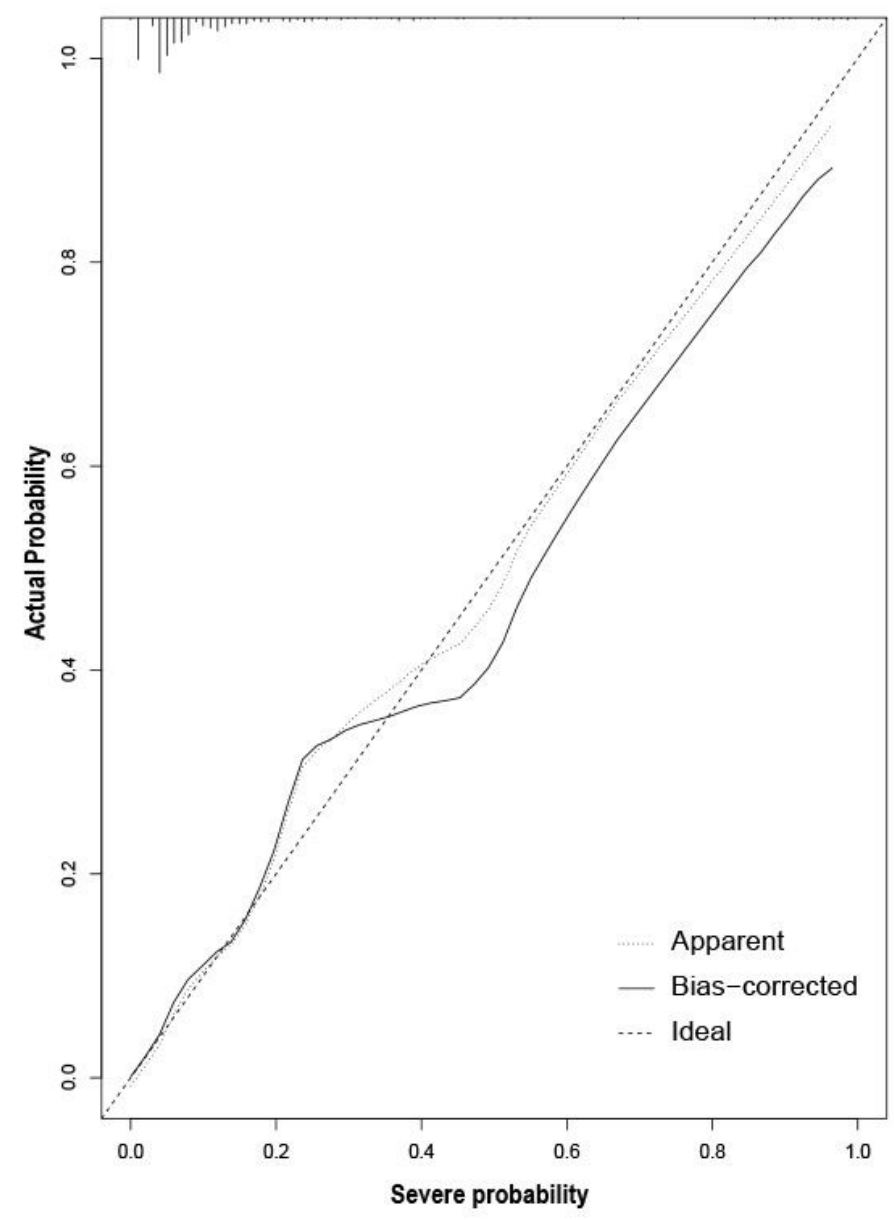

B

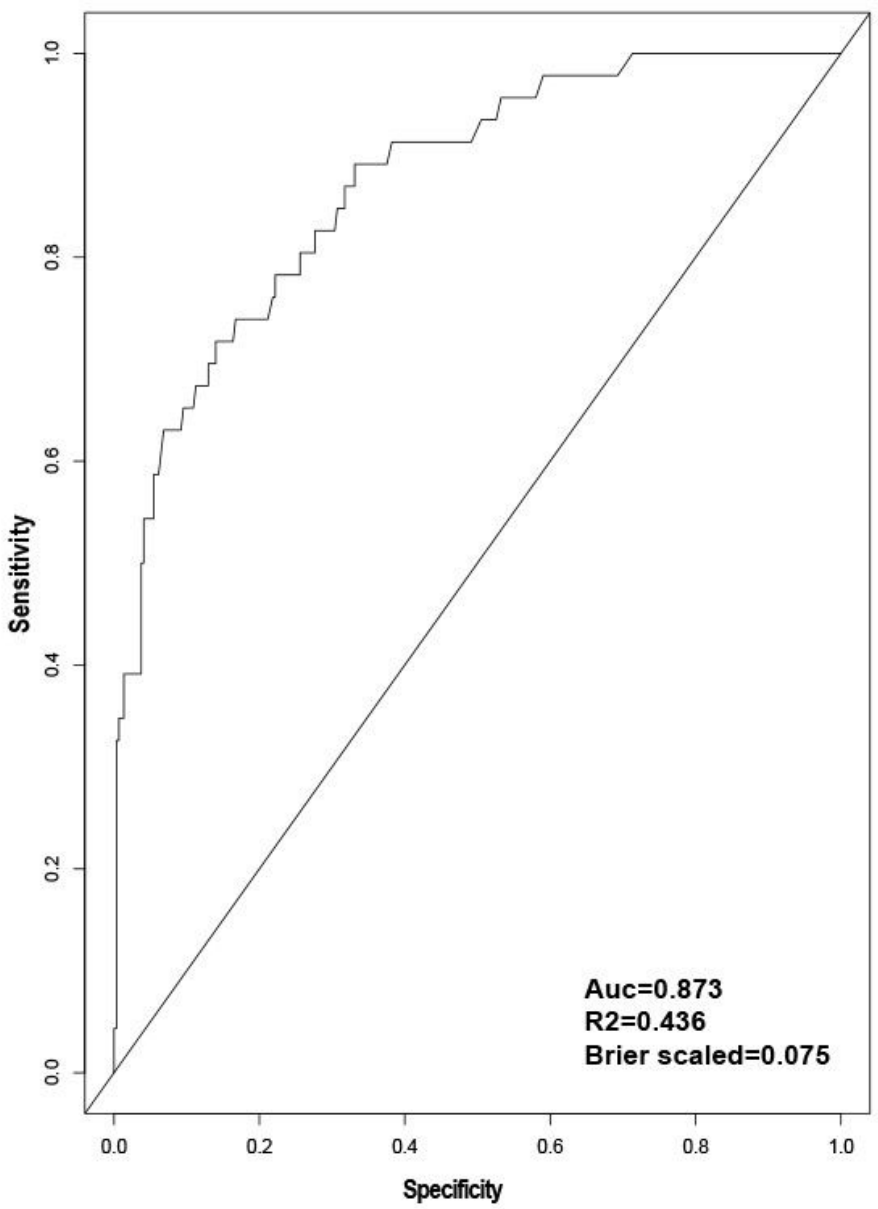

Figure 2

Consistency and sensitivity analysis of nomogram score in the training cohort A. The prediction accuracy of continuous correction curve detection model. B. Consistency and sensitivity of ROC curve detection model. 
A

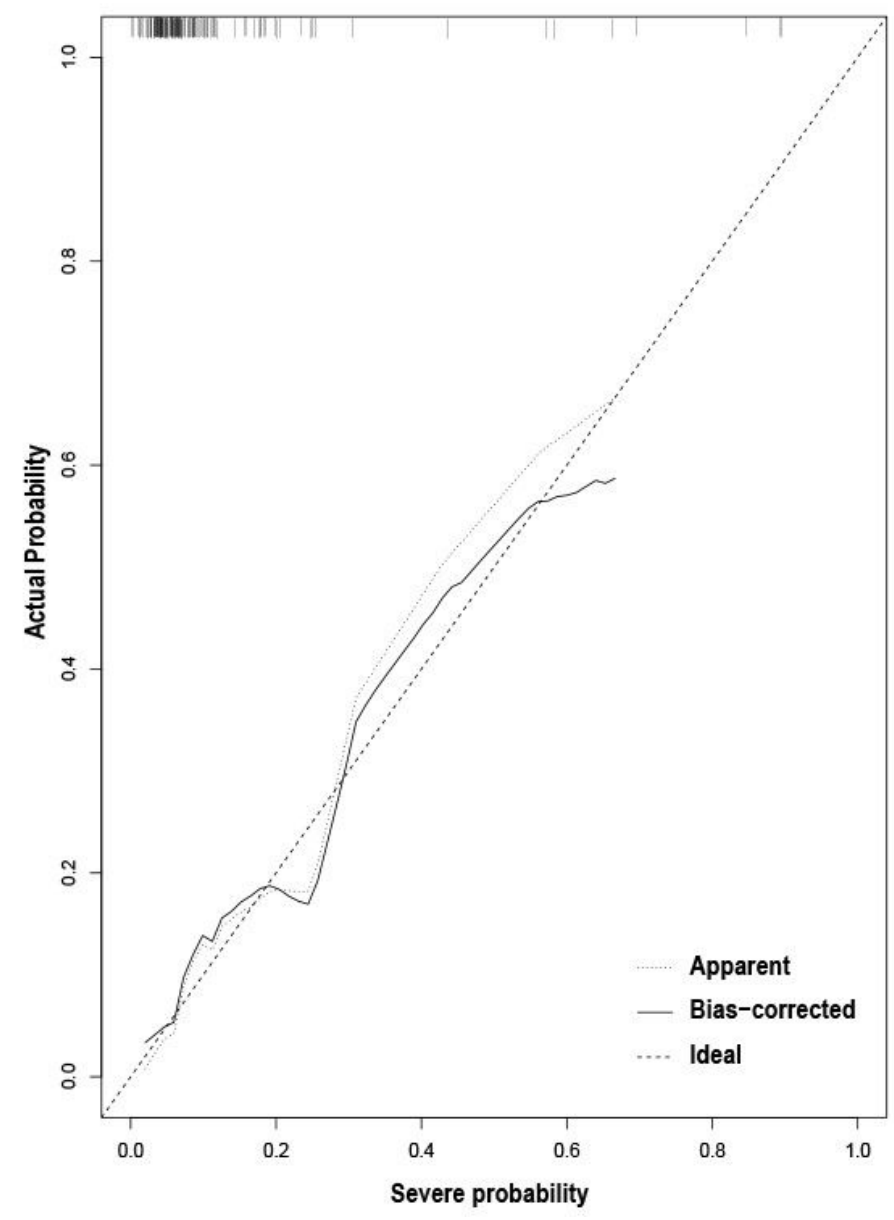

B

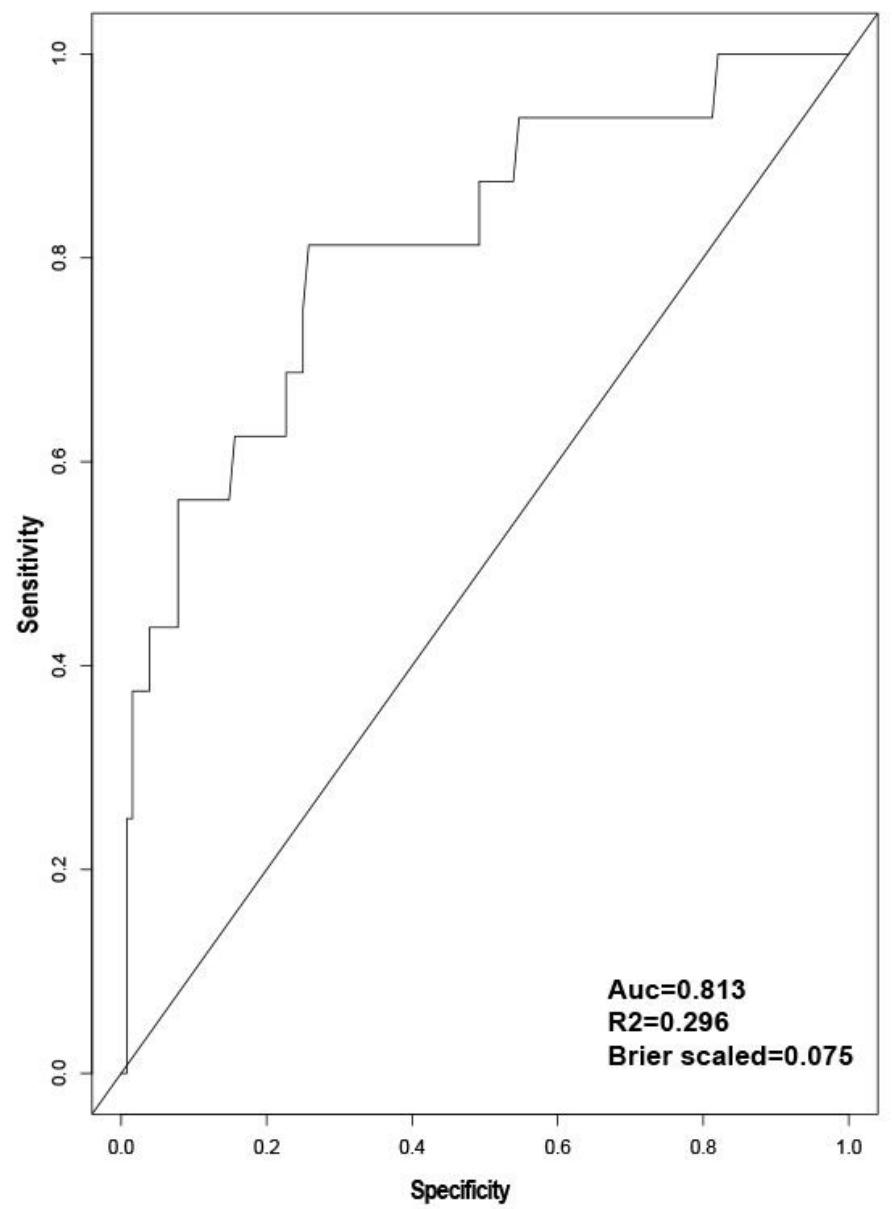

Figure 3

Consistency and sensitivity analysis of nomogram score in the validation cohort. A. The prediction accuracy of continuous correction curve detection model. B. Consistency and sensitivity of ROC curve detection model.

\section{Supplementary Files}

This is a list of supplementary files associated with this preprint. Click to download.

- highlights.docx

- titlepage.docx 